\title{
Abolishing Toxicity of Copper by Some Environmental Factors Using Green Alga Chlorella vulgaris
}

\author{
${ }^{1}$ Adel A. Fathi, ${ }^{2,3}$ Mohamed M. Azooz and ${ }^{3}$ Mohamed A. Al-Fredan \\ ${ }^{1}$ Department of Botany and Microbiology, \\ Faculty of Science, El-Minia University, El-Minia, Egypt \\ ${ }^{2}$ Department of Botany, Faculty of Science, South Valley University, Qena, Egypt \\ ${ }^{3}$ Department of Biological Sciences, \\ College of Science, King Faisal University, Al-Hassa, Saudi Arabia
}

Received 2012-10-24, Revised 2012-12-30; Accepted 2012-12-30

\begin{abstract}
A variety of environmental factors are known to modify the toxicity of heavy metals on algae. This study was undertaken to examine the impact of some inorganic and organic complexes on the toxicity of copper using the isolated algal species (Chlorella vulgaris). The data illustrate that the amount of available forms of copper (copper free ions) gradually decreased with increasing the concentrations of all tested inorganic and organic complexes (carbonates, EDTA, Glycine and calcium). The toxicity of a metal is controlled by the concentrations of the available form (s) and not by the total concentration of the metal. In other words, the availability and the toxicity depend on the concentrations of the different physico-chemical forms (speciation) of the metals in their natural environments.
\end{abstract}

Keywords: Copper, Chlorella, Environmental Factors, Toxicity

\section{INTRODUCTION}

The physico-chemical climate of natural waters controls the metal speciation sometimes resulting in very low and practically un measurable concentrations of the most available metal forms. Such low concentrations may lead to metal-limitation (Fathi and Falkner, 1997). However, the requirements and sensitivities of essential and toxic metals of different algal species are not the same. The dinoflagellateceratiumhirundella e.g., is more sensitive to copper than the green algae Nannochlorisa and Ourococcus sp. (McKnight, 1991). Generally, diatoms are also more sensitive to toxic metals than green and blue-green algae (Fathi and El-Shahed, 1998; Fathi and Zaki, 1999). This species-dependent metal sensitivity and the ecosystem-dependent metal availabilities might influence the composition of phytoplankton communities. Thus, metal availability might play a selective role in phytoplankton succession.
A variety of environmental factors are known to modify the toxicity of heavy metals on algae (Fathi, 2002; Janssen et al., 2003; Fathi et al., 2000; Afkar et al., 2010). One of the most important of these factors concerns the determination of biological availability and the metals physiochemical state (Langston, 1990). Metal adsorption (Sequesterization) on to water borne particles or complexation with dissolved organics generally will reduce metal toxicity. However, in the natural environment it is often difficult or even impossible to characterize the form in which the metal exists (Lobban and Harrison, 1996). The objective of this study was to examine the impact of carbonates, EDTA, Glycine and calcium on the toxicity of copper using the isolated algal species (Chlorella vulgaris). Copperis known to be common in the Saudipolluted waters (Al-Kahtani and Fathi, 2008; Fathi et al., 2009; Youssef et al., 2009; AlSheikh and Fathi, 2010) and accordingly was chosen for experimentation.

Corresponding Author: Adel A. Fathi, Department of Botany and Microbiology, Faculty of Science, El-Minia University, El-Minia, Egypt 


\section{MATERIALS AND METHODS}

\subsection{Organism and Culture Condition}

Chlorella vulgaris Beyerinck was isolated from AlAsfar Lake, Al-Hassa, Saudi Arabia. Isolation and purification were made by dilution and plating technique method. The alga was grown in $250 \mathrm{~mL}$ flasks containing $100 \mathrm{~mL} \mathrm{Kuhl} \mathrm{(1962)} \mathrm{and} \mathrm{incubated} \mathrm{in} \mathrm{an}$ illuminated incubator (Precision, USA) at $22^{\circ} \mathrm{C}$ and irradiance at $150 \mu \mathrm{mol} \mathrm{m} \mathrm{m}^{-2} \mathrm{~s}^{-1}$, provided by cool white fluorescent lamps set on $14: 10 \mathrm{~h}$ photoperiod. All cultures were shaken twice daily to prevent cells from clumping. Sterile technique was used at all times.

\subsection{Determinations of Chlorophyll $a$ Content}

Chlorophyll a content was estimated in acetone extract according to Jeffrey and Humphery (1975). The content of the pigment fractions $(\mu \mathrm{g} \mathrm{chl} / \mathrm{mL}$ algal suspension) was then calculated under consideration of the dilution factors, using the following equations:

$$
\text { - Chlorophyll } \mathrm{a}=11.93 \mathrm{~A}_{664}-1.93 \mathrm{~A}_{630}
$$

\subsection{Algal Counting}

Cell number was determined using a Hematocytometer Chamber. Hemacytometer $0.1 \mathrm{~mm}$ deep, having improved Naubauer ruling was used. One drop of the algal suspension was pipetted on the slide, covered and left for 2 min for algal settling. The mean counts of three replicates were taken into consideration and the data were given as cell $/ \mathrm{mL}$ algal suspension.

\subsection{Environmental Influence on Metal Toxicity}

On these experiments, the effect of carbonates, EDTA, Glycine and calcium on the toxicity of copper was carried out in $250 \mathrm{~mL}$ Erlenmeyer flasks that contained $100 \mathrm{~mL}$ of Khul's nutrient medium. Copper was eliminated as were all known chelators (Ferric citrate, citric acid and $\mathrm{Na}_{2}$-EDTA) and trace metal levels were reduced to1/20th of the level in Khul's medium. Cultures were grown at $27 \pm 1.0^{\circ} \mathrm{C}$ on a $16 \mathrm{~h}$ light: $8 \mathrm{~h}$ dark cycle with a light intensity $70 \mu \mathrm{moL} \mathrm{m} \mathrm{m}^{-2} \mathrm{~s}^{-1}$. Modified Khul's medium was supplied with the sublethal concentrations of copper $\left(10^{-6} \mathrm{M}\right)$. This concentration suggested after a previous screening experiment (data not shown). The addition of the abovementioned treatments did not exert a large change on the $\mathrm{pH}$ of the medium. All cultures started with $\mathrm{pH} 6.8$ and remained unchanged throughout the incubation period. All assays were conducted using three replicates.

\subsection{Effect of Carbonates on Metal Toxicity}

Different concentrations of sodium carbonates $(0.5,1.0$, 2.0, 3.0 and $4.0 \mathrm{mgL}^{-1}$ ) were added to the culture flasks contains nutrient medium and $10^{-6} \mathrm{M}$ copper (Sub-lethal concentration).A standard initial inoculum of the isolated alga was inoculated to the culture flasks. At the end of the incubation period ( 7 days), a $20-\mathrm{mL}$ aliquot from each standing culture were filtered through a dried $0.45 \mu \mathrm{m}$ membrane filter (Schleicher and Schull, Germany). Chl. $a$ was estimated in acetone extract according to Jeffrey and Humphery (1975) and cell number was determined using a Hematocytometer Chamber.

\subsection{Effect of Calcium on Metal Toxicity}

Based on preliminary experiments, four calcium concentrations (as calcium chloride) were selected $(5,10$, 20, 40 and $100 \mathrm{mgL}^{-1}$ ), which are representative of AlAsfar lake (Fathi et al., 2009). The sub lethal of copper $\left(10^{-6} \mathrm{M}\right)$ was supplemented by the five test concentrations of calcium. A standard initial inoculum of the Chlorella vulgaris was inoculated to the culture flasks. Flasks were incubated under the same conditions used to culture the algae for seven days period.

\subsection{Effect of EDTA on Metal Toxicity}

Prior to the experiment Ethylendiaminetetraacetic Disodium salt (EDTA-Na) at concentrations (2.0, 4.0, 8.0, 16.0 and $32.0 \mathrm{mgL}^{-1}$ ) was added the copper cultures at sub-lethal concentration. All culture flasks were left for 7 days, the growth parameters (Chl. $a$ and cell number) were measured.

\subsection{Effect of Glycine on Metal Toxicity}

An initial inoculum of the tested isolated alga was inoculated into $100 \mathrm{~mL}$ of sterile Kuhl's nutrient medium Erlenmeyer flasks of $250 \mathrm{~mL}$ capacity. The cultures were supplied with $10^{-6} \mathrm{M}$ copper and various concentrations of glycine $\left(0.1,0.15,0.2,0.25\right.$ and $\left.0.3 \mathrm{mgL}^{-1}\right)$. These concentrations were suggested after some preliminary experiments. After the incubation period, the growth parameters were measured according to the previously mentioned method.

\subsection{Speciation Modeling}

Metal speciation (The amount of free metal ions) in used medium was calculated with the chemical equilibrium software MINEQL ${ }^{+}$(Version 4.6).

\subsection{Statistics}

The calculated values are the mean of triplicates, the standard deviation was less than $5 \%$ of these mean values. 


\section{RESULTS}

It is apparent that metal toxicity can be heavily influenced by environmental conditions. Binding of metals to organic materials, precipitation, complexation and ionic interactions, are important phenomena that must be considered carefully in laboratory and filed studies. This study aimed to examine the impact of inorganic complexes (Carbonate and calcium) and organic complexes (EDTA and glycine) on the toxicity of $\mathrm{Cu}^{2+}$ using the isolated algal species (Chlorella vulgaris).

In this experiments different concentrations of sodium carbonates $\left(0.1,0.15,0.2,0.25\right.$ and $\left.0.3 \mathrm{mgL}^{-1}\right)$ were added to the culture flasks contains nutrient medium and $10^{-6} \mathrm{M}$ copper (Sub-lethal concentration).All culture flasks were inoculated by initial inoculums of Chlorella vulgaris. As illustrated in Fig. 1 the inhibitory effect of $10^{-6} \mathrm{M}$ of copper on the growth (Cell number and Chl. a content) of Chlorella vulgaris increased gradually with increasing the carbonate concentrations up to $0.20 \mathrm{~g} \mathrm{~L}^{-1}$, where the cell number reached the maximum. By increasing the carbonate concentration more than $0.20 \mathrm{mg} \mathrm{L}^{-1}$ the inhibitory effect appeared again. On the other hand, the data of Fig. 2 shows that the amounts of copper free ions calculated by the chemical equilibrium software (MINEQL+V. 4.6) were decreased by increasing carbonate concentrations.

Follow the detoxifying role of calcium on copper toxicity, calcium at five concentrations $(5,10,20,40$ and $100 \mathrm{mgL}^{-1}$ ) was added to culture medium supplemented by $10^{-6} \mathrm{M}$ copper (Sub-lethal concentration). The data of Fig. 3 show that the applications of calcium at all concentrations stimulate the cell number and chlorophyll $a$ contents of the tested alga as compared to the control. The data of Fig. 4 indicate that, the addition of calcium had a negative effect on amount of the calculated free copper ions. This phenomenon was more pronounced at higher calcium levels. Generally, one can deduce that calcium treatments alleviate the inhibitory effects of copper.

Figure 5 reveals that the addition of different concentrations of EDTA (2.0, 4.0, 8.0, 16.0 and 32.0 $\mathrm{mgL}^{-1}$ ) to the Chlorella vulgaris at the sub-lethal concentration of copper $\left(10^{-6} \mathrm{M}\right)$ promoted the growth of alga. The maximum cell number and Chl.a content appeared at the culture treated by $4.0 \mathrm{mgL}^{-1}$ EDTA. Above this concentration the growth parameters were decreased. The data also illustrate that the amount of available forms of copper (copper free ions) gradually decreased with increasing the concentrations of EDTA (Fig. 6).

Follow the beneficial effect of amino acids on heavy metals toxicity, different concentrations of exogenous glycine $\left(0.1,0.15,0.2,0.25\right.$ and $\left.0.3 \mathrm{mgL}^{-1}\right)$ were supplied to culture medium supplemented by $10^{-6} \mathrm{M}$ copper. The data of Fig. 7 clearly demonstrated that in the presence of exogenous glycine, the measured growth parameters of Chlorella was promoted in a manner dependent on the amino acid concentration in the medium. It should be noted that started from the concentrations $0.2 \mathrm{mgL}^{-1}$ of glycine the values of growth parameters remained constant. In addition the data of Fig. 8 revealed that the amounts of copper free ions calculated by the chemical equilibrium software were decreased by increasing glycine concentrations.

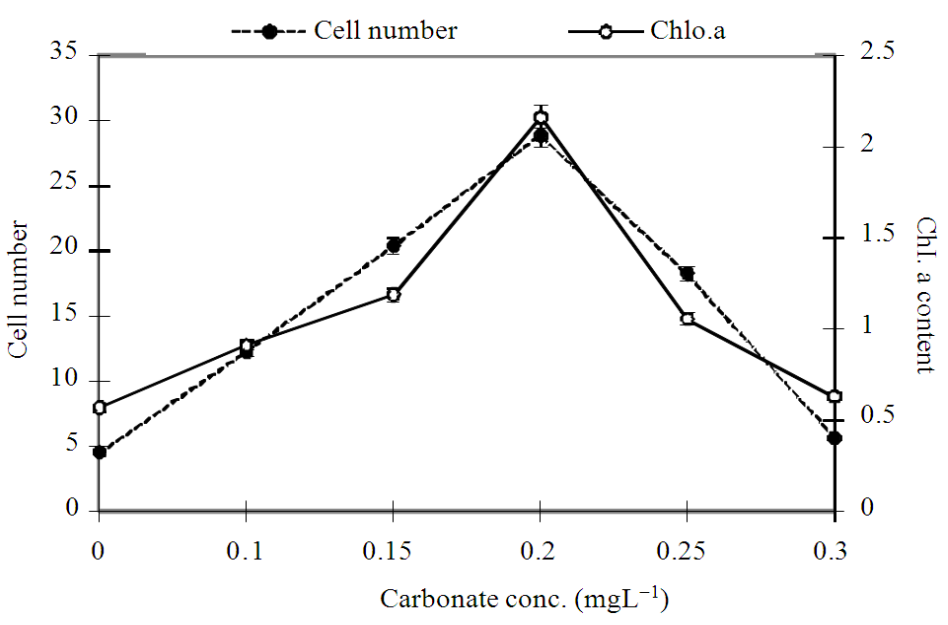

Fig. 1. Effect of carbonate on the cell number $\left(\right.$ No. $\left.\times 10^{-6} \mathrm{~L}^{-1}\right)$ and Chl.a content $\left(\mathrm{mgL}^{-1}\right)$ of Chlorella vulgaris at copper concentration $10^{-6} \mathrm{M}$ (the sub lethal concentration) 
Adel A. Fathi et al. / American Journal of Environmental Science 8 (6) (2012) 633-641

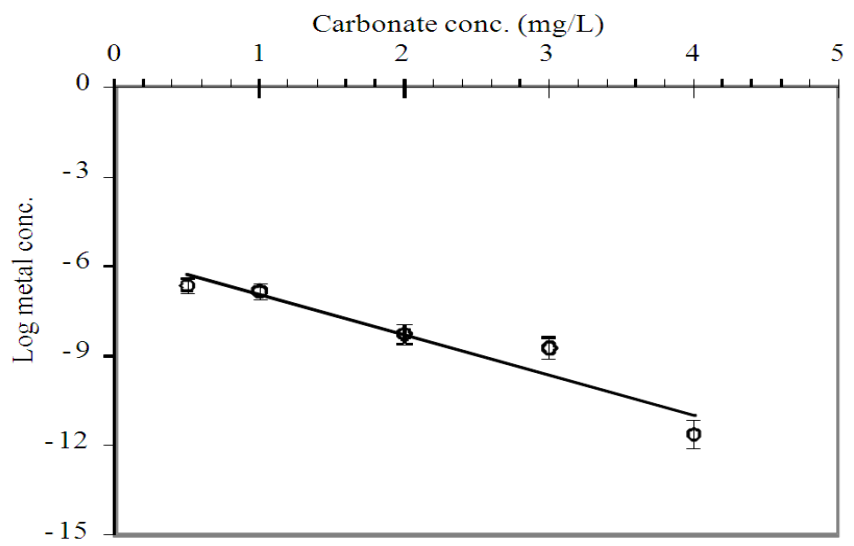

Fig. 2. The amounts of copper free ions calculated by the chemical equilibrium software (MINEQL+ V.4.6) at various concentrations of carbonate

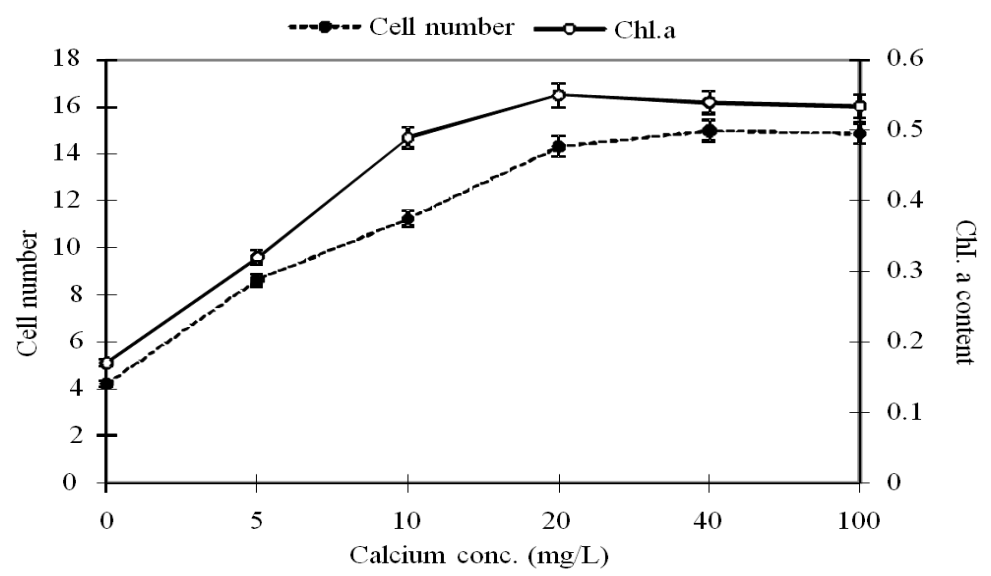

Fig. 3. Effect of calcium on the cell number $\left(\right.$ No. $\left.\times 10^{-6} \mathrm{~L}^{-1}\right)$ and Chl. a content $\left(\mathrm{mgL}^{-1}\right)$ of Chlorella vulgaris at copper concentration $10^{-6} \mathrm{M}$ (the sub lethal concentration)

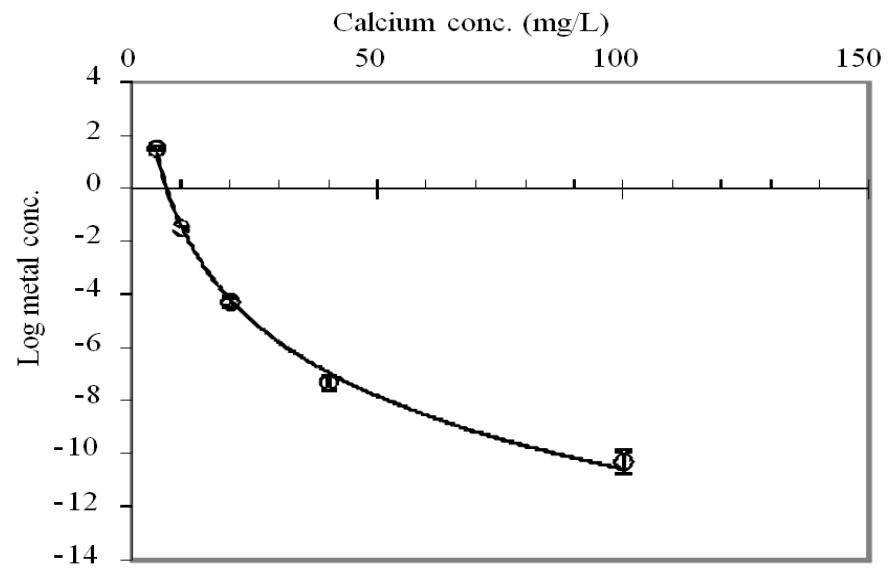

Fig. 4. The amounts of copper free ions calculated by the chemical equilibrium software (MINEQL+ V.4.6) at various concentrations of Calcium 
Adel A. Fathi et al. / American Journal of Environmental Science 8 (6) (2012) 633-641

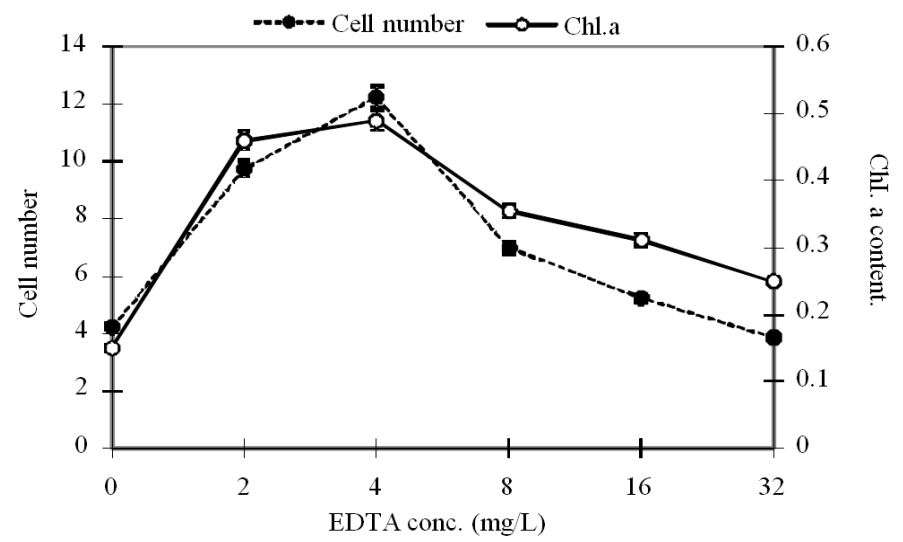

Fig. 5. Effect of EDTA on the cell number (No. $\left.\times 10^{-6} \mathrm{~L}^{-1}\right)$ and Chl. a content $\left(\mathrm{mgL}^{-1}\right)$ of Chlorella vulgaris at copper concentration $10^{-6} \mathrm{M}$ (the sub lethal concentration)

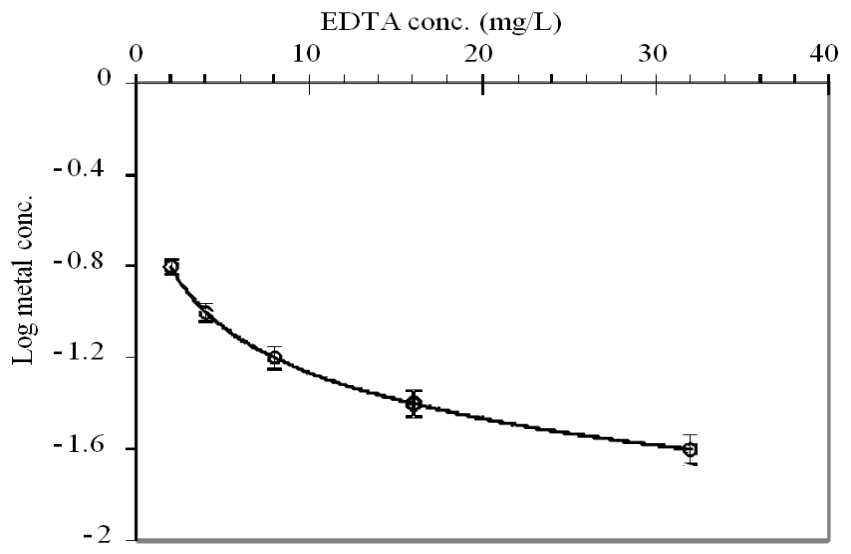

Fig. 6. The amounts of copper free ions calculated by the chemical equilibrium software (MINEQL+ V. 4.6) at various concentrations of EDTA

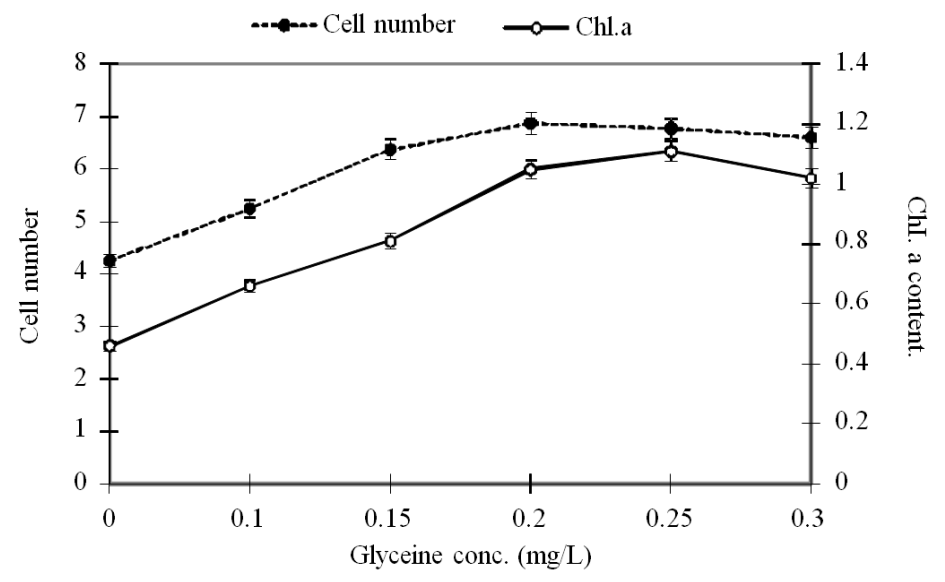

Fig. 7. Effect of glycine on the cell number $\left(\right.$ No. $\left.\times 10^{-6} \mathrm{~L}^{-1}\right)$ and Chl.a content $\left(\mathrm{mgl}^{-1}\right)$ of Chlorella vulgaris at copper concentration $10^{-6} \mathrm{M}$ (the sub lethal concentration) 


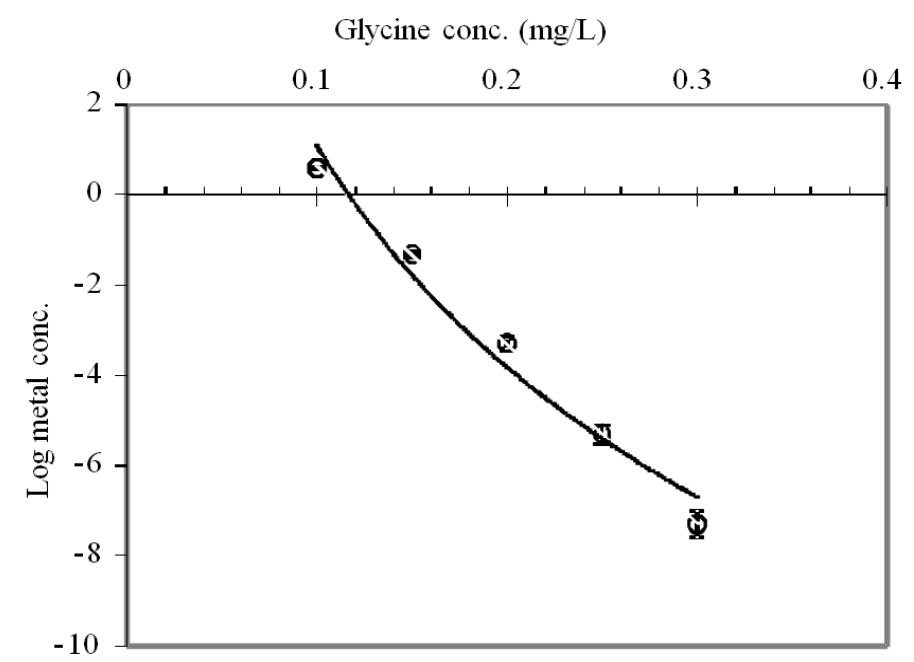

Fig. 8. The amounts of copper free ions calculated by the chemical equilibrium software (MINEQL+ V. 4.6) at various concentrations of Glycine

Generally, the data clearly indicate that the effect of exogenous glycine on the values of measured growth parameters and the amount of copper free ions were found to be less in compare to the other tested factors (carbonates, EDTA and calcium). Thereby the impact of glycine on the copper toxicity is weak.

\section{DISCUSSION}

Aquatic environments are often exposed to various pollutants like heavy metals that are released from industrial, agricultural and domestic wastes. Emissions of heavy metals can then enter all ecosystems and bring about severe problems in plants, especially algae depending on the concentrations of a given element (Muwafq and Bernd, 2006). There are a remarkable number of investigations demonstrating the toxic effects of heavy metals on different species of algae (Fathi et al., 2005; Osman et al., 2004; Akira et al., 2005; Muwafq and Bernd, 2006; Anne et al., 2006; Afkar et al., 2010).

Natural waters attain their chemical composition through a variety of chemical reactions and physicochemical process. The term speciation refers to the particular physical and chemical forms in which an element occurs. Metal speciation in aquatic environment is determined by several factors (Solubility; Redox potential (Eh); Acidity (pH); Alkalinity; Salinity; Nature and concentrations of organic matter; Nature and concentrations of suspended materials). This complication results from the often complex chemical properties of metals and the chemical composition of rivers, lakes and seas (Francois, 1983). According to the vast majority of studies on metal uptake by aquatic biota, the free ion activity, $\left(\mathrm{M}^{2+}\right)$, reflects the metal's chemical activity, which in turn determines the importance of the metal's reactions with the biologically active surface binding sites (Francois et al., 2007; Afkar et al., 2010; Nikiforova and Kozlov, 2011).

In this study, the use of carbonate reduced the toxicity of copper at sub lethal concentration indicating role of carbonate in reducing copper toxicity. In aqueous solution, carbonate, bicarbonate, carbon dioxide and carbonic acid exist together in a dynamic equilibrium. The chemical composition of fresh water is directly or indirectly influenced by the fate of carbon compounds. Dissolution of carbon dioxide in water leads to the formation of carbonic acid and carbonates. A further consequence of carbon dioxide dissolution is a change in the $\mathrm{pH}$. These two parameters control the amount of the available metals free ions (Fathi and El-Shahed, 1998). The inhibitory effect appeared at higher concentration of carbonate might be attributed to change in $\mathrm{pH}$ of the medium. On the other hand, the decreasing of copper toxicity (copper free ions) resulting from carbonate treatments can be attributed to the complexation of copper and precipitation it on the form of copper carbonates complex leading to a reduction in metal bioavailability and toxicity

Calcium is known to be a good inhibitor of divalent metal uptake in algae (Hauck et al., 2002; Slaveykova and Wilkinson, 2002; Mosulen et al., 2003; Kola and Wilkinson, 2005; Afkar et al., 2010). The data of this investigation clearly shows that calcium alleviated the 
toxic effects of copper. Some studies suggested that calcium affects heavy metal toxicity to microbiota and it is playing an important role in ameliorating metal toxicity to algae (Zaki, 1999; Zaki and Fathi, 2004). This protective role is confirmed by cytological investigations (Pellegrini et al., 1993). It has been suggested that an antagonistic interaction between copper and calcium which could be explained by a competition phenomenon due to their very similar ionic (Fernandez-Pinas et al., 1995). Other Studies (Charels et al., 2007) have generally indicated that metal toxicity is reduced by $\mathrm{Ca}$ and/or $\mathrm{Mg}$, due to either competition for cell surface binding sites or solution speciation changes resulting from metal complexation and/or coprecipitation. From our point of view, the reduction of copper toxicity by calcium could be due to the formation of calcium-metal complex compound (metal speciation). Therefore the calcium can have considerable effects on the availabilities and the bioaccumulation and thus the toxicity of copper.

The data of this study revealed that the addition of EDTA at different concentrations promoted the growth of Chlorella vulgaris. However, the amount of copper free ions gradually decreased with increasing the concentrations of EDTA. EDTA is known to protect algae, fungi and other microbes against toxicity of metals by precipitation, co-precipitation, complex formation and reduction of metal uptake (Khalil, 1991). This amino acid is widely used to sequester di and trivalent metalions. EDTA binds to metals via four carboxylate and two amine groups. Organic and inorganic chelators significantly decrease the copper toxicity and also affect its uptake (Diny et al., 1994; Fathi and El-Shahed, 1998). According to Irving-Williams series (Francois, 1983) copper is one of the metals expected to be most complexed by EDTA. Therefore, EDTA reduces the toxicity of copper due to the reduction of the available forms of ions by the formation of strong copper-EDTA complex. On the other hand, the higher concentrations of EDTA (more than $4 \mathrm{mgL}^{-1}$ ) decreased the growth of Chlorella vulgaris.Tubbing et al. (1994) reported that copper-EDTA complexes and un-ioinized salts $\left(\mathrm{CuCO}_{3}\right)$ were dominant copper species in synthetic solutions inhibiting photosynthesis. Generally, it can conclude that EDTA, up to certain concentrations can reduce copper toxicity, while at higher concentrations it was toxic to algae.

Of the organic compounds identified in natural waters, amino acids are the major class with sizeable complexation affinities for metals. On this investigation, the effect of glycine on the toxicity of copper was studied. The data shows that the growth of Chlorella was found to be promoted in compared to the control, which in turn confirming the detoxification role of glycine on metal toxicity. The presence of both a carboxyl and an amino group gives all amino acids the ability to coordinate metals at two positions and they are among the simplest chelating agents. On the other hand, the calculated amount of copper free ions was found to be decreased by glycine treatments. Stumm and Morgan (1981) reported that the most reactive elements in complex-formation with amino acids are mercury, iron and copper. Accordingly, the reduction of copper toxicity could be attributed to the formation of copperglycine complex (unavailable forms), thereby decreasing the concentrations of free copper ions (available forms) in the external medium. This may be partly attributable to the reduction in copper toxicity. The protective role of amino acids against heavy metal toxicity was studied by some authors (Fathi and Zaki, 2003; Osman et al., 2004). Fathi and Zaki (2003) showed a positive relationship between copper toxicity and proline accumulation in Chlorella vulgaris. Osman et al. (2004) reported that $\mathrm{Ni}^{2+}$ stimulated the biosynthesis of glycine, alanine and histidine and highly stimulated valine and sulphur containing amino acids (cystine and methionine) in N. perminuta.

\section{CONCLUSION}

Very low concentrations of metals may limit algal growth, however, higher concentrations of available forms of metal become optimal and maximum growth rate can be reached. At still higher concentrations inhibition of the growth occurs and the metal becomes toxic or even lethal. Thus the toxicity of a metal is controlled by the concentrations of the available form (s) and not by the total concentration of the metal. In other words, the availability and the toxicity depend on the concentrations of the different physico-chemical forms (speciation) of the metals in their natural environments.

\section{ACKNOWLEDGEMENT}

We thank Deanship of Scientific Research, King Faisal University and the Deanship members for financial support (Grant No: 120138). 


\section{REFERENCES}

Afkar, E., H. Ababna and A.A. Fathi, 2010. Toxicological response of the green alga chlorella vulgaris, to some heavy metals. Am. J. Environ. Sci., 6: 230-237. DOI: 10.3844/ajessp.2010.230.237

Akira, S., Q.V. Litiana, K. Norihide and M. Shigetoh, 2005. Evaluation of the sensitivity of marine microalgal strains to the heavy metals, $\mathrm{Cu}, \mathrm{As}, \mathrm{Sb}$, $\mathrm{Pb}$ and $\mathrm{Cd}$. Environ. Int., 31: 713-722. DOI: doi:10.1016/j.envint.2005.01.001

Al-Kahtani, M.A. and A.A. Fathi, 2008. Physiological studies on tilapia fish (Oreochromis niloticus) as influenced by the cyanobacterial toxins microcystin. J. Biol. Sci., 8: 1226-1230.

Al-Sheikh, H. and A.A. Fathi, 2010. Ecological studies on al-asfar lake, al-hassa, saudi arabia, with special references to the sediment. Res. J. Environ. Sci., 4: 13-22. DOI: $10.3923 /$ rjes.2010.13.22

Anne, H.L.J., C. Marie, D. Veronique, B. Jean-Francois and L. Jean-Franc, 2006. Effect of copper sulphate treatment on natural phytoplanktonic communities. Aquat. Toxicol., 80: 267-280. DOI: 10.1016/j.aquatox.2006.09.004

Charels, A., S.Markich, J.Stauber and L.F.D. Filippis, 2007. The effect of water hardness on the toxicity of uranium to a tropical freshwater alga (Chlorella sp.). Aquatic Toxicol., 60: 61-73. DOI: 10.1016/S0166445X(01)00260-0

Diny, M.J.D., A.F.M.I. Wim, R.C. Mohammed, I. Dik Van and V. Wilko, 1994. The contribution of complexed copper to the metabolic inhibition of algae and bacteria in synthetic media and river water. Water Res., 28: 37-44. DOI: 10.1016/00431354(94)90117-1

Fathi, A.A. and A.M. El-Shahed, 1998. Response of Nile water phytoplankton to some heavy metals and their interaction with carbonate and EDTA. J. Union Arab Biol., Cairo., 6: 1-12.

Fathi, A.A. and F.E.T. Zaki, 1999. Effects of wastewater disposal into the river Nile on the water quality and phytoplankton communities, at El-Minia, Egypt. ElMinia Sci. Bull., 2: 99-110.

Fathi, A.A. and F.E.T. Zaki, 2003. Role of proline level in ameliorating heavy metal toxicity in Scenedesmusbijuga. El-Minia Sci. Bull., 14: 155-167.

Fathi, A.A. and G. Falkner, 1997. Adaptation to elevation of the concentration of the trace element copper during growth of Scenedesmus bijuga is reflected in the properties of the copper uptake system. J. Trace Microprobe Techniques, 15: 321-333.
Fathi, A.A., 2002. Toxicological response of the green alga Scenedesmus bijuga to mercury and lead. Folia Microbiol., 47: 667-671. PMID: 12630317

Fathi, A.A., F.T. Zaki and A.A. Fathy, 2000. Bioaccumulation of some heavy metals and their influence on the metabolism of Scenedesmusbijugaand Anabaena spiroides. Egypt J. Biotechnol., 7: 293-307.

Fathi, A.A., F.T. Zaki and H.A. Ibraheim, 2005. Response of tolerant and wild type strains of Chlorella vulgaris to copper with special references to copper uptake system. Protistology, 4: 73-78.

Fathi, A.A., M.A. Al-Fredan and A.M. Youssef, 2009. Water quality and phytoplankton communities in lake al-asfar, al-hassa, Saudi Arabia. Res. J. Environ. Sci., 3: 505-513.

Fernandez-Pinas, F., P. Mateo and I. Bonilla, 1995. Cadmium toxicity in Nostoc UAM208: protection by calcium. New Phytol., 131: 403-407. DOI: 10.1111/j.1469-8137.1995.tb03077.x

Francois, L., C. Fortin and P.G.C. Campbell, 2007. pH modulates transport rates of manganese and cadmium in the green alga Chlamydomonas reinhardtii through non-competitive interactions: Implications for an algal BLM. Aquatic Toxicol., 84: 123-132. DOI: 10.1016/j.aquatox.2007.02.019

Francois, M. M,. 1983. Principles of Aquatic chemistry. A wiley-Interscience Publication, John Wiley and Sons. Inc. ISBN-10: 0471086835, pp.446.

Hauck, M., C. Mulack and A. Paul, 2002. Manganese uptake in the epiphytic lichens Hypogymnia physodes and Lecanora conizaeoides. Environ. Exp. Bot., 48: 107-117. DOI: 10.1016/S00988472(02)00014-X

Janssen, C.R., D.G. Heijerick, K.A. De schamphelaer and H.E. Allen, 2003. Environmental risk assessment of metals: Tools for incorporating bioavailability. Environ. Int., 28: 793-800. DOI: 10.1016/S0160-4120(02)00126-5

Jeffrey, S.W. and G.F. Humphery, 1975. New spectrophotometric equations for determining chlorophyll $\mathrm{a}, \mathrm{b}$ and $\mathrm{c}$ in higher plants, algae and natural populations. Biochem. Physiol. Pflanzen, 167: 185-199.

Khalil, Z., 1991. EDTA and the uptake and accumulation of $63 \mathrm{Ni}$ by Phormidium fragile. Egypt. J. Micrbiol., 26: 377-385.

Kola, H. and K.J. Wilkinson, 2005. Cadmium uptake by a green alga can be predicted by equilibrium modelling. Environ. Sci. Technol., 39: 3040-3047. PMID: 15926550 
Kuhl, A., 1962. The physiology of inorganic condensed phosphates in Chlorella. Vorlrag Bot. Hrsg. Deut. Botan. Ges., 1: 157-166.

Langston, W.J., 1990. Toxic Effects of Metal and the Incidence of Metal Pollution in Marine Ecosystem. In: Heavy Metals in the Marine Environment, Furness, R.W. and P.S. Rainbow, (Eds.), CRC Press, pp: 101-1022.

Lobban, C.S. and P.J. Harrison, 1996. Seaweed Ecology and Physiology. 1st Edn., Cambridge University Press, New York, ISBN-10: 0521408970, pp: 384.

McKnight, D.M., 1991. Chemical and biological processes controlling the response of a freshwater ecosystem to copper stress: a field study of the CuSO4 treatment of Mill Pond Reservoir, Burlington, Massachusetts. Limnol. Oceanogr.

Mosulen, S., M.J. Domınguez, J. Vigara, C. Vilchez and A.Guiraum et al., 2003. Metal toxicity in Chlamydomonasreinhardtii. effect on sulfate and nitrate assimilation. Biomol. Eng., 20: 199-203. DOI: 10.1016/S1389-0344(03)00053-4

Muwafq, H.M. and M. Bernd, 2006. Toxicity of heavy metals on Scenedesmusquadricauda (Turp.) de brebisson in batch cultures. Environ. Sci. Pollut. Res., 13: 98-104. DOI: 10.1065/espr2005.07.274

Nikiforova, T.E. and V.A. Kozlov, 2011. Various factors affecting heavy metal ion sorption from aqueous media by sorbent containing cellulose. Protect. Metals Phys. Chem. Surfaces, 47: 20-24. DOI: $10.1134 / \mathrm{S} 2070205110051016$

Osman, M.E.H., A.H. El-Naggar, M.M. El-Sheekh and E. El-Mazally, 2004. Differential effects of $\mathrm{Co}^{2 \square}$ and $\mathrm{Ni}^{2 \square}$ on protein metabolism in Scenedesmusobliquus and Nitzschiaperminuta. Environ. Toxicol. Pharmacol., 16: 169-178. DOI: 10.1016/j.etap.2003.12.004
Pellegrini, M., A. Laugier, M. Sergent, R. Phan-Tan-Luu and R.Valls et al., 1993. Interactions between the toxicity of the heavy metals cadmium, copper, zinc in combinations and the detoxifying role of calcium in the brown alga Cystoseriabarbata. J. Applied Phycol., 5: 351-361. DOI: 10.1007/BF02186238

Slaveykova, V.I. and K.J. Wilkinson, 2002. Physicochemical aspects of lead bioaccumulation by Chlorella vulgaris. Environ. Sci. Technol., 36: 969975. DOI: $10.1021 / \mathrm{es} 0101577$

Stumm, W. and J.J. Morgan, 1981. Aquatic Chemistry. 2nd Edn., Wiely, New York, pp: 780.

Tubbing, D.M.J., W. Admiraal, R.F.M.J. Cleven, M. Iqbal and D.V.D. Meent et al., 1994. The contribution of complexed copper to the metabolic inhibition of algae and bacteria in synthetic media and river water. Water Res. 28: 37-44. DOI: 10.1016/0043-1354(94)90117-1

Youssef, A.M., M.A. Al-Fredan and A.A. Fathi, 2009. Floristic composition of lake al-asfar, alahsa, Saudi Arabia. Int. J. Botany, 5: 116-125. DOI: 10.3923/ijb.2009.116.125

Zaki, F.T. and A.A. Fathi, 2004. Impact of copper on some physiological aspects of NostocMuscorum with special references to the detoxifying role of calcium. ActaBotanicaHungarica, 46: 3-4. DOI: 10.1556/ABot.46.2004.3-4.14

Zaki, F.T., 1999. Effect of Boron and Calcium on growth and nitrogen fixation of the blue-green alga CalothrixParietina. Folia Microbiol., 44: 201-204. DOI: $10.1007 / \mathrm{BF} 02816243$ 